\title{
Triple Band-Notched UWB Antenna using Meandered Ground Stubs
}

\author{
Y. F. Weng, S. W. Cheung and T. I. Yuk \\ Department of Electrical and Electronic Engineering \\ The University of Hong Kong, Hong Kong \\ E-mail: [yfweng, swcheung, tiyuk]@eee.hku.hk
}

\begin{abstract}
In this paper, three pairs of meandered ground stubs are used to create a triple band-notched characteristic for a compact planar-monopole antenna used in the ultrawide band (UWB). The three band notches include the IEEE 802.16 (WiMax) band (3.3-3.6 GHz), the lower wireless area network (WLAN) band (5.15-5.35 GHz) and the higher WLAN band (5.725-5.825 $\mathrm{GHz})$. The center frequencies and bandwidths of the notches can be adjusted using the dimensions of the meandered ground stubs. Prototype of the proposed antenna is designed and fabricated. The band-notched characteristics, return loss, radiation patterns, peak gains and efficiencies of the antenna are studied using both computer simulation and measurements.
\end{abstract}

Keywords - monopole antenna, ultrawideband (UWB) antenna, multiple band notched, meandered ground stub.

\section{INTRODUCTION}

Since the US-FCC authorized the unlicensed use of the ultra-wideband (UWB) frequency spectrum in the range of 3.1 to $10.6 \mathrm{GHz}$ with an emission limit of $-41.3 \mathrm{dBm} / \mathrm{MHz}$ for commercial applications in 2002 [1], industry and academia have put in tremendous efforts on researches relating to antenna designs for UWB systems. UWB communication systems operating in such a wide frequency band and low power emission level could easily be interfered by the nearby communication systems such as the IEEE 802.16 (WiMax) system operating from 3.3 to $3.6 \mathrm{GHz}$ and WLAN system having the lower and upper bands of 5.15-5.35 GHz and 5.725$5.825 \mathrm{GHz}$, respectively, in the US [2]. The interference levels caused by the nearby systems can be suppressed by using bandstop filters, but this will increase the cost and system complexity and require more space when integrated with other microwave circuits.

One possible solution to this problem is to design the UWB antennas with band-notched characteristics. Different design methods have been proposed to implement the band-notched characteristic for UWB planar monopole antennas [3-14], e.g. using parasitic elements [4], folded strips [5], split-ring resonators (SRRs) [6,7], quarter wavelength tuning stubs [8], meandered ground stubs [9], resonated cells on the microstrip feed line or coplanar waveguide (CPW) fractal structure $[10,11]$, slots on the radiator [12] and resonators (filters) along the antenna feed line [13-14]. However, most of the these designs have only a single notched band.

In this paper, we propose to use three pairs of meandered ground stubs to realize a triple band-notched characteristic for a compact UWB monopole antenna fed with a microstrip line. When current is flowing on a microstrip line, it mainly distributes on the edges of it. Thus we propose to implement meandered ground stubs along the upper edges of the ground plane and the feed line to create the desired notched bands. The design is studied using the computer simulation tool CST MWS [15] and the Satimo Starlab measurement system. The UWB antenna is designed to have three notches covering the WiMax frequency band, the lower and upper WLAN bands at the center frequencies of $3.45 \mathrm{GHz}, 5.25 \mathrm{GHz}$, and $5.775 \mathrm{GHz}$, respectively. The simulated and measured results on the radiation patterns, peak gains and efficiencies agree well. Simulation and measurement results show that the proposed UWB antenna has an operating frequency range from 2.68 $\mathrm{GHz}$ to over $11.15 \mathrm{GHz}$ with return loss $\geqslant 10 \mathrm{~dB}$ which fully satisfies the requirement for UWB applications.

\section{ANTENNA DESIGN}

\section{Structure of the multiple band-notched UWB antenna}

In our UWB antenna design, we propose to use the planarmonopole technology to achieve a compact size for applications in wireless devices. The UWB antenna consists of an elliptical radiator fed by a $50-\Omega$ microstrip line and a rectangular ground plane below the substrate, as shown in Fig. 1. To achieve a triple band-notched characteristic, three pairs of meandered ground stubs are used to create three notches separately in the WiMax, the lower WLAN and the upper WLAN bands. To create a band notch in the WiMax frequency band, a pair of meandered ground stubs is symmetrically etched on the upper edges of the ground plane with a distance of $w_{3}$ from the center of the microstrip feed line, as shown in Fig. 1 (d). To create two more notches in the lower and upper WLAN bands, two more pairs of meandered ground stubs are symmetrically placed at a distance of $d_{3}$ from the microstrip feed line and connected to ground through separate vias with radius $R_{\text {via }}$, as shown in Fig. 1 (c).

The antenna is designed on a Polytetrafluoroethylene (PTFE) substrate PCB with a transverse dimension of $30 \mathrm{~mm} \times$ $39.3 \mathrm{~mm}$, a relative dielectric constant $\varepsilon_{r}=3.5$, a thickness 0.8 $\mathrm{mm}$ and a loss tangent 0.003 . For good impedance matching, the width of the microstrip feed-line is varied gradually, from $w_{1}=1.73 \mathrm{~mm}$ near to the feed point to $w_{2}=0.6 \mathrm{~mm}$ near to the radiator. The distance, gap, between the elliptical radiator and the upper edge of ground is also quite critical for impedance matching and so has been optimized, using the computer simulation software tool CST MWS, to be $0.3 \mathrm{~mm}$. Detailed 
dimensions of the triple band-notched antenna are listed in Table 1.

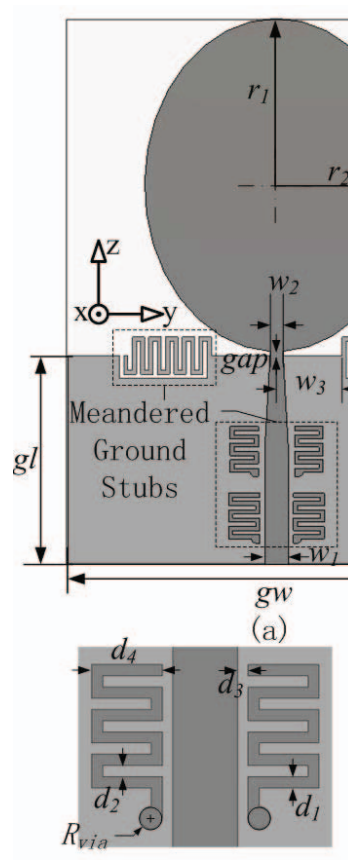

(c)

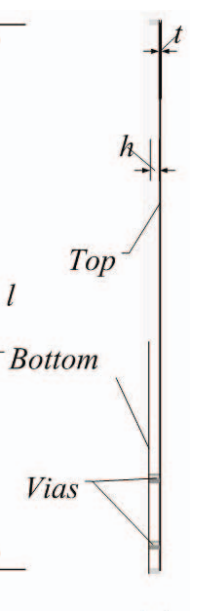

(b)
Fig. 1 Structure of proposed band notched antenna. (a) top view, (b) side view and (c) meandered ground stubs.

\section{TABLE I. BAND-NOTCHED UWB ANTENNA DIMENSIONS}

\begin{tabular}{|c|c|c|c|}
\hline Parameter & Value(mm) & Parameter & Value(mm) \\
\hline$g l$ & 15 & $d_{1}$ & 0.3 \\
\hline$g w$ & 30 & $d_{2}$ & 0.3 \\
\hline$l$ & 39.3 & $d_{3}{ }^{a}$ & 0.25 \\
\hline$r_{1}$ & 12 & $d_{4}{ }^{a}$ & 2.2 \\
\hline$r_{2}$ & 9 & $d_{3}{ }^{b}$ & 0.3 \\
\hline$t$ & 0.035 & $d_{4}{ }^{b}$ & 2 \\
\hline$H$ & 0.762 & $d_{5}$ & 0.3 \\
\hline$R_{\text {via }}$ & 0.4 & $d_{6}$ & 0.3 \\
\hline$g a p$ & 0.3 & $d_{7}$ & 0.3 \\
\hline$w_{1}$ & 1.73 & $d_{8}$ & 2.7 \\
\hline$w_{2}$ & 0.6 & $w_{3}$ & 5.2 \\
\hline $\begin{array}{l}\text { a For notch at lower WLAN band } \\
\text { b For notch at higher WLAN band }\end{array}$ & &
\end{tabular}

\section{Parametric study}

A parametric study of the band-notched UWB antenna has been conducted by computer simulation to explore how the dimensions of the meandered ground stubs affect the performances of band notches. Results have shown that the meandered stubs act like resonators. The pair of meandered stubs on the upper edge of the ground plane prevents the signal from passing through them at resonance. While for the other two pairs placed along the feed line, at resonance, the signal is coupled from the feed line to the meandered stubs and then flowing to ground through the vias. This prevents the signal from flowing through the feed line into the elliptical radiator and radiating to free space. The lengths $d_{4}$ and $d_{8}$ of the elements in the meandered stubs of Figs. 1(c) and (d), respectively, determine the inductances of the resonators (i.e., the meandered ground stubs). The distances $d_{2}$ and $d_{6}$ between the adjacent elements and distances $d_{3}$ and $d_{7}$ between the feed line and meandered stubs, respectively, determine the capacitances of the resonators.

Computer simulation results on the effects of $d_{2}, d_{3}$ and $d_{4}$ on the return loss of the antenna are shown in Figs. 2, 3 and 4, respectively. It can be seen that $d_{2}$ and $d_{4}$ determine the center frequency of the notch and $d_{3}$ mainly affects the bandwidth of the notch. These plots also reveal that when the values of $d_{2}, d_{3}$ and $d_{4}$ are changed, the return loss in the rest of the UWB band remains about the same. These properties provide the designers with a great freedom to select the notched-band frequency and bandwidth for the antenna.

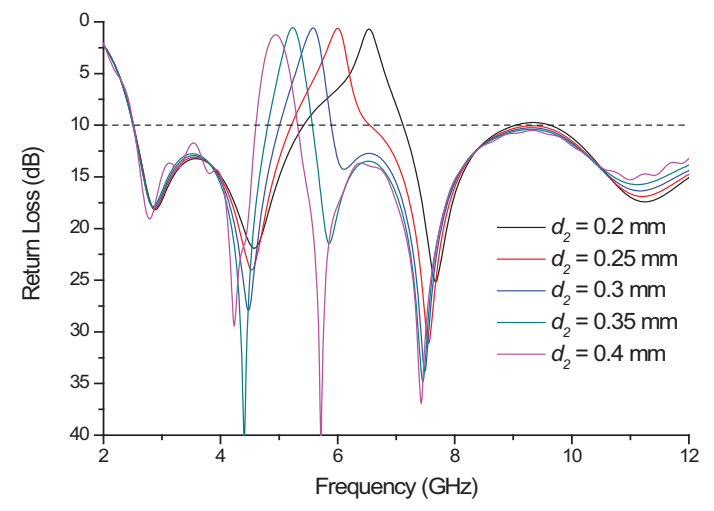

Fig. 2 Return loss for different values of $d_{2}$ with other dimensions fixed.

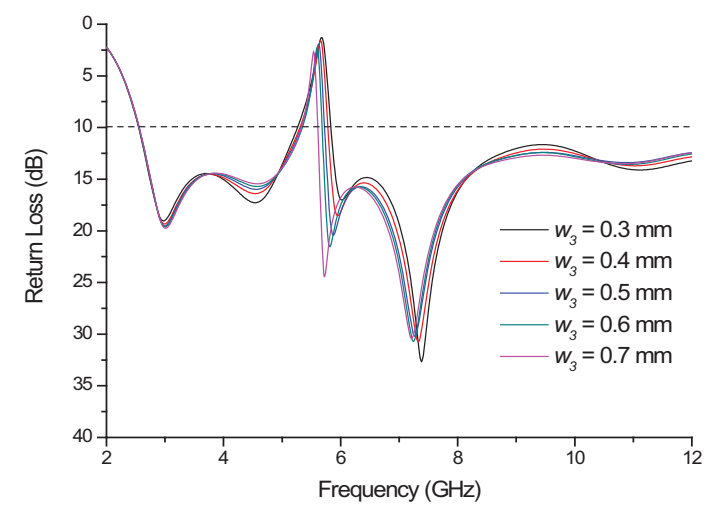

Fig. 3 Return loss for different values of $d_{3}$ with other dimensions fixed.

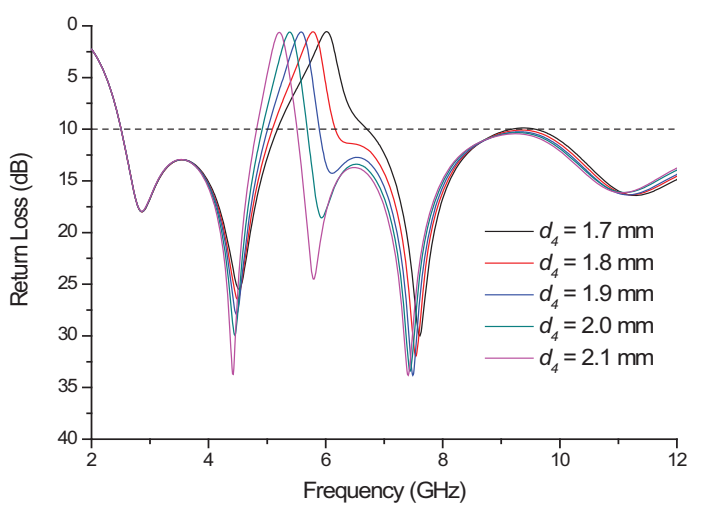

Fig. 4 Return loss for different values of $d_{4}$ with other dimensions fixed. 


\section{RESULTS AND DISCUSSIONS}

The design of our triple band-notched antenna has been fabricated, using a PCB with PTFE substrate with parameters described previously, as shown in Fig. 5. The return loss, peak gains and efficiencies across the UWB band, and the radiation patterns at $2,3.45,5.25,5.775$ and $11 \mathrm{GHz}$ have been simulated using the CST MWS and measured using the Satimo Starlab measurement system.

The simulated and measured return loss of the antennas are shown in Fig. 6. It can be seen that, the antenna can operate from $2.68 \mathrm{GHz}$ to $11.15 \mathrm{GHz}$ with return loss $\geqslant 10 \mathrm{~dB}$ which fully satisfies the FCC UWB requirements. In the three desired notched bands, the measured return loss is substantially less than $10 \mathrm{~dB}$. The measured bandwidths with return loss $<10 \mathrm{~dB}$ of the proposed antenna at three notch bands are listed in Table II.

TABLE II. MEASURED NotCh BANDWIDTHS WITH RETURN LOSS $<10$ $\mathrm{DB}$

\begin{tabular}{|c|c|c|c|}
\hline & WiMax Band & Lower WIAN Band & Upper WLAN Band \\
\hline Required & $3.3-3.6 \mathrm{GHz}$ & $5.15-5.35 \mathrm{GHz}$ & $5.725-5.825 \mathrm{GHz}$ \\
\hline Measured & $3.37-3.85 \mathrm{GHz}$ & $5.07-5.43 \mathrm{GHz}$ & $5.63-5.82 \mathrm{GHz}$ \\
\hline $\begin{array}{c}\text { Measured } \\
\text { Notch } \\
\text { Bandwidth }\end{array}$ & $480 \mathrm{MHz}$ & $360 \mathrm{MHz}$ & $190 \mathrm{MHz}$ \\
\hline
\end{tabular}

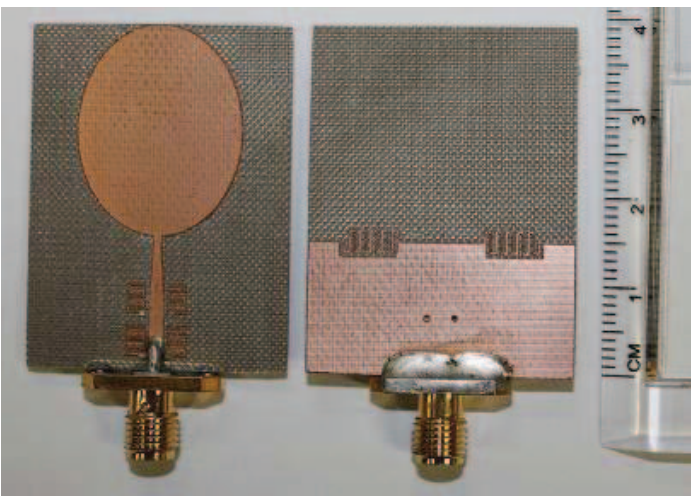

Fig. 5 Photograph of proposed multiple band-notched antenna.

The simulated and measured radiation patterns of the antenna at the frequencies of $2,3.45,5.25,5.775$ and $11 \mathrm{GHz}$ in the two principle planes, $x-y$ and $x-z$ planes, are shown in Fig. 7. At 2 and $11 \mathrm{GHz}$, Figs. 7(a) and 8(i) show that the antenna has approximately omnidirectional radiation patterns in the $x-y$ plane. In the $x-z$ plane patterns, Figs. 7(b) and 8(j) show that there are two nulls at the positive and negative $\mathrm{Z}$ directions. These characteristics are similar to those of a typical monopole antenna. The radiation patterns in Figs. 7(c) and 8(d) for $3.45 \mathrm{GHz}$, in Figs. 7(e) and 8(f) for $5.25 \mathrm{GHz}$, and in Figs. $7(\mathrm{~g})$ and $8(\mathrm{~h})$ for $5.775 \mathrm{GHz}$ indicate that the gains are almost evenly suppressed in all directions in the three notched bands by the meandered ground stubs and the average gain is about $10 \mathrm{dBi}$.

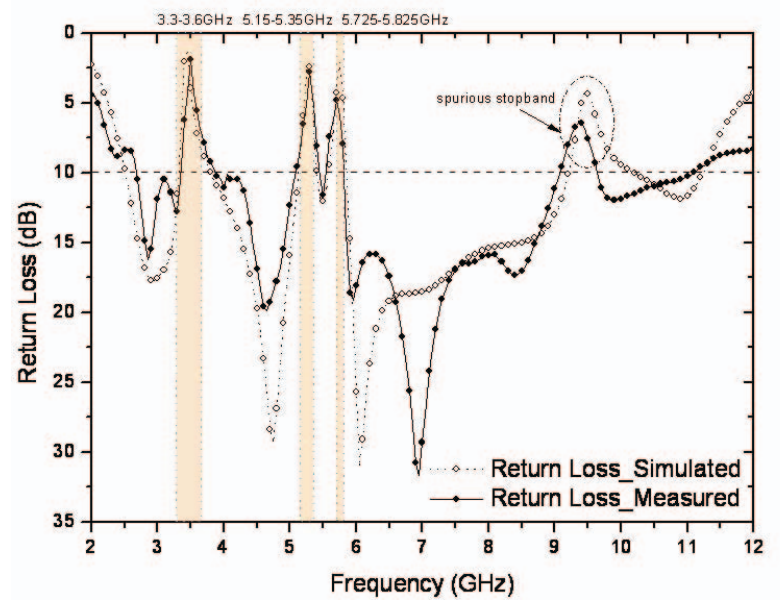

Fig. 6 Simulated and measured return loss
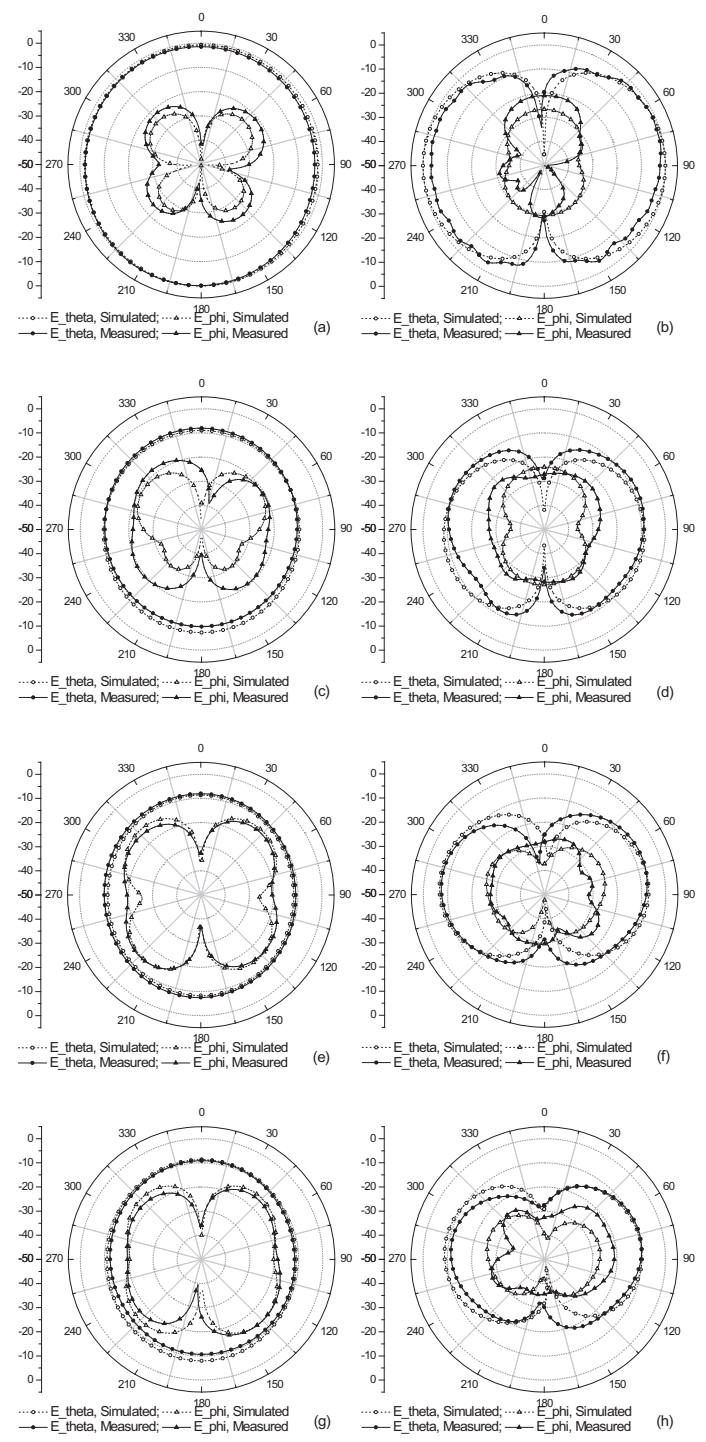


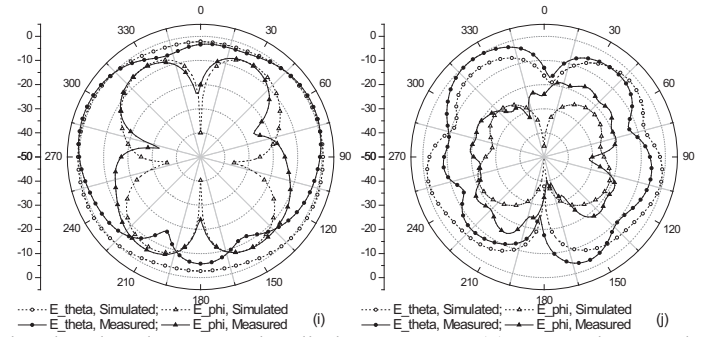

Fig. 7 Simulated and measured radiation patterns. (a) $2 \mathrm{GHz}$ in $\mathrm{x}-\mathrm{y}$ plane; (b) 2 $\mathrm{GHz}$ in $\mathrm{x}-\mathrm{z}$ plane; (c) $3.45 \mathrm{GHz}$ in $\mathrm{x}-\mathrm{y}$ plane; (d) $3.45 \mathrm{GHz}$ in $\mathrm{x}-\mathrm{z}$ plane; (e) $5.25 \mathrm{GHz}$ in $\mathrm{x}-\mathrm{y}$ plane; (f) $5.25 \mathrm{GHz}$ in $\mathrm{x}-\mathrm{z}$ plane; (g) $5.775 \mathrm{GHz}$ in $\mathrm{x}-\mathrm{y}$ plane; (h) $5.775 \mathrm{GHz}$ in $\mathrm{x}-\mathrm{z}$ plane; (i) $11 \mathrm{GHz}$ in $\mathrm{x}-\mathrm{y}$ plane; and (j) $11 \mathrm{GHz}$ in $\mathrm{x}-\mathrm{z}$ plane.

Finally, the simulated and measured peak gains and efficiencies of the antenna are shown in Figs. 8 (a) and (b), respectively. The measured antenna peak gain is between 2 $4.75 \mathrm{dBi}$ over the UWB operating frequency range, except in the notch bands. At the three notched bands, significant reductions in gain and radiation efficiency can be observed. In the WiMax, lower WLAN and upper WLAN frequency bands, the antenna gain is suppressed to $-3.4 \mathrm{dBi},-2.3 \mathrm{dBi}$ and -2.1 $\mathrm{dBi}$, respectively. The radiation efficiency is between $55 \%$ $99 \%$, but substantially reduced to $14.6 \%, 15.2 \%$ and $22.8 \%$, respectively, in these frequency bands. These results indicate that the meandered ground stubs work effectively to introduce a triple band-notched characteristic for the UWB antenna.

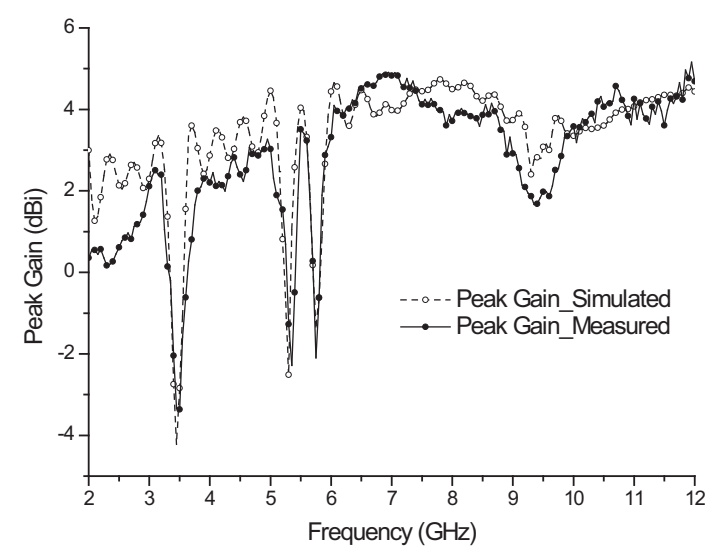

(a)

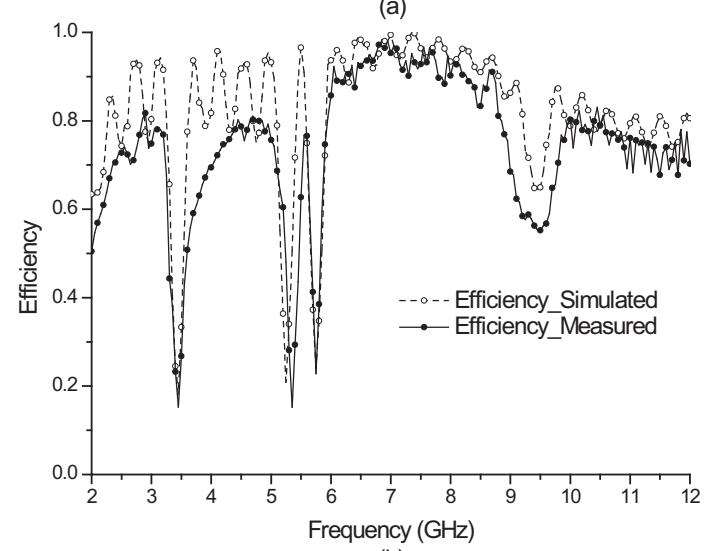

(b)

Fig. 8 Simulated and measured (a) peak gain and (b) efficiency.

\section{CONCLUSIONS}

In this paper, meandered ground stubs have been proposed to design a triple band-notched characteristic for compact planar-monopole UWB antennas. The proposed idea has been used to design a compact UWB antenna. Studies using computer simulation and measurement on the return loss, antenna patterns, peak gains and radiation efficiencies of the UWB antenna have been carried out. Results have shown that the antenna has approximately omnidirectional radiation patterns with good band notched characteristic.

\section{REFERENCES}

[1] "Federal Communications Commission Revision of Part 15 of the Commission's Rules Regarding Ultra-Wideband Transmission Systems," FCC, 2002, First Report and Order FCC, 02.V48.

[2] Availanle on: http://www.fcc.gov/pshs/techtopics/techtopics10.html .

[3] Schantz, Hans, Glenn Wolenec, Edward (Mike) Myszka, "Frequency notched UWB antennas," IEEE Conference on Ultra Wideband Systems and Technologies. Reston, Virginia, Nov, 2003.

[4] K. Kim, Y. Cho, S. Hwang, and S. Park, "Band-notched UWB planar monopole antenna with two parasitic patches," Electron. Lett., vol. 41, no. 14, pp. 783-785, Jul. 2005.

[5] T. G. Ma and S. J. Wu, "Ultrawideband band-notched folded strip monopole antenna," IEEE Trans. Antennas Propag., vol. 55, no. 9, pp. 2473-2479, Sep. 2007.

[6] J. Kim, C. S. Cho and J. W. Lee, "5.2 GHz notched ultra-wideband antenna using slot-type SRR,” Electron. Lett., vol. 42, no. 6, pp. 315316, Mar. 2006.

[7] Y.F. Weng, S.W. Cheung and T.I. Yuk, "An Antenna For UWB and Bluetooth Standards with Band-Notched Characteristic" 2009 IEEE International Conference on Ultra-Wideband (ICUWB), 9-11 September 2009, Vancouer, Canada.

[8] A. Kerkhoff and H. Ling, "Design of a planar monopole antenna for use with ultra-wideband (UWB) having a band-notched characteristic," in IEEE AP/S Int. Symp. Dig., 2003, vol. 1, pp. 830-833.

[9] Y.F. Weng, W.J. Lu, S.W. Cheung and T.I. Yuk, "UWB Antenna with Single or Dual-Band Notched Characteristic for WLAN Band using Meandered Ground Stubs" 2009 Loughborough Antennas \& Propagation Conference, 16-17 November 2009, Loughborough, UK.

[10] S.W. Qu, J.L. Li and Q. Xue, "A Band-Notched Ultrawideband Printed Monopole Antenna," IEEE Antennas and Wireless Progag Lett, vol. 5, pp. 495-498, 2006.

[11] W. J. Lui, C. H. Cheng, Y. Cheng, and H. Zhu, "Compact Frequency notched ultra-wideband microstrip slot antenna with fractal tuning stub," Electron. Lett., vol. 41, no.6, pp.294-296, Mar., 2005.

[12] Y.J. Cho, K.H. Kim, D.H. Choi, S.S. Lee and S.O. Park, "A miniature UWB planar monopole antenna with $5 \mathrm{GHz}$ band-rejection filter," IEEE Trans. Antennas and Propag, vol. 54, issue 5, pp. 1453-1460, Oct, 2005.

[13] E. Pancera, D. Modotto, A. Locatelli, F.M. Pigozzo and C. De Angelis, "Novel Design of UWB Antenna with Band-Notch Capability," European Conference on Wireless Technologies, pp 48-50, Munich, Dec, 2007.

[14] S.H. Lee, J.W. Baik and Y.S. Kim, “A COPLANAR WAVEGUIDE FED monopole ultra-wideband antenna having band-notched frequency function by two folded-stripline," Microw. Opt. Tech. Lett., vol. 49, issue 11, pp. 2747-2750, Aug. 2007.

[15] Available on: http://www.cst.com. 